\title{
Effect of Aluminum Oxide Nanoparticles Films Thickness on Optical Properties
}

\author{
I.H. Hilal ${ }^{1}$, H. l. Abdullah ${ }^{2}$ and A. M. Ibraheem ${ }^{3}$ \\ ${ }^{1,3}$ Solar energy research Center, Renewable energy Directorate, Higher education and scientific research \\ Ministry, Baghdad, Iraq. \\ ${ }^{2}$ Al- Mustansiriah University, College of Science, Department of Chemistry, Baghdad, Iraq.
}

esrra.hadi@yahoo.com

\begin{abstract}
:
The aluminum oxide $\left(\mathrm{Al}_{2} \mathrm{O}_{3}\right.$ ) nanoparticles thin films has been prepared via UV-irradiation methods using metal salts (aluminum nitrate $\left.\mathrm{Al}\left(\mathrm{NO}_{3}\right)_{3}\right)$ with different thickness $(150,200,300$, and 400) and measuring structural and optical properties.

The structure of the $\left(\mathrm{Al}_{2} \mathrm{O}_{3}\right)$ nanoparticles thin films was tested with X-Ray showed that have six main diffraction features corresponding to (111), (311), (222), (400), (511) and (440) planes . The results of atomic force microscopy ( AFM ) indicated that all films have grain size about $25.97-65 \mathrm{~nm}$.

The optical band gap energy was decreased by the increase of thickness from (5.19-4.68) eV then used aluminum oxide as gas sensor.
\end{abstract}

Keywords: X-Ray, AFM, Optical Properties.

\section{Introduction}

Aluminum oxide $\left(\mathrm{Al}_{2} \mathrm{O}_{3}\right)$ is a multifunctional material used as polycrystalline material. The transparent conductive oxide widely used in various applications, such as solar cells. optoelectronics [1,2] significant p-type of $\mathrm{Al}_{2} \mathrm{O}_{3}$ efforts through chemical and electrochemical deposition of compound (especially semiconductor)

$\mathrm{AL}_{2} \mathrm{O}_{3}$ is a semiconductor that process optical properties which in all deposition techniques used $\mathrm{AL}_{2} \mathrm{O}_{3}$, films are polycrystalline where the grain boundary, and the effect on the barrier high were studied [3].

Structural properties of undoped $\mathrm{AL}_{2} \mathrm{O}_{3}$ films deposited by spray pyrolysis at temperatures $395 \mathrm{k}$ have been studied by so many researches.

\section{Materials and Methods}

The $\mathrm{AL}_{2} \mathrm{O}_{3}$ were prepared by $\mathrm{Al}\left(\mathrm{NO}_{3}\right)_{3}$ dissolved in water from an aqueous solution of $(0.1 \mathrm{M})$, While the cell contains a quartz tube as a jacket for immersion UV- source in the solution, the reactor is cooled by

ice bath to avoid the rising in temperature as a result of the UV-irradiation.

Then using spray polyrises system as explain in points:

1-Substrate temperature of about (400k)

2-Spray rate $5 \mathrm{sec} / 1 \mathrm{~min}$

3 -Air pressure (2N/M2)

This films of nano $\mathrm{AL}_{2} \mathrm{O}_{3}$ prepared by using each of spray nozzle and substrate after cleaning and heating on electrical heater for (30min) before spraying process so the glass substrate is nearly at the same temperature as the electric heater.

Each spraying period lasts for about $(15 \mathrm{sec})$ following spraying, the film has smooth surface free from pinholes using weighting methods and electronic balance. The thin film was estimated by using the equation:

$$
\mathrm{t}_{(\mathrm{nm})}=\mathrm{m}
$$




\section{Results and Discussion:}

1-Structral properties

I. X-Ray peaks appeared in (2Ө) at 20 from 80 degrees

The pattern has six main diffraction features corresponding to (111), (311), (222), (400), (511) and (440) planes and all the three peaks can be indexed to standard cubic phase of $\mathrm{Al}_{2} \mathrm{O}_{3}$ (JCPDS card No. 870598,870720 and 893722). No reflection peaks corresponding to nitrate ions and other impurities were noted in this pattern, indicating the high purity of the final product as illustrated in figure (1). The different peak intensity profile was characteristic of cubic structure of $\mathrm{Al}_{2} \mathrm{O}_{3}$ This result is somewhat consistent with the [4].

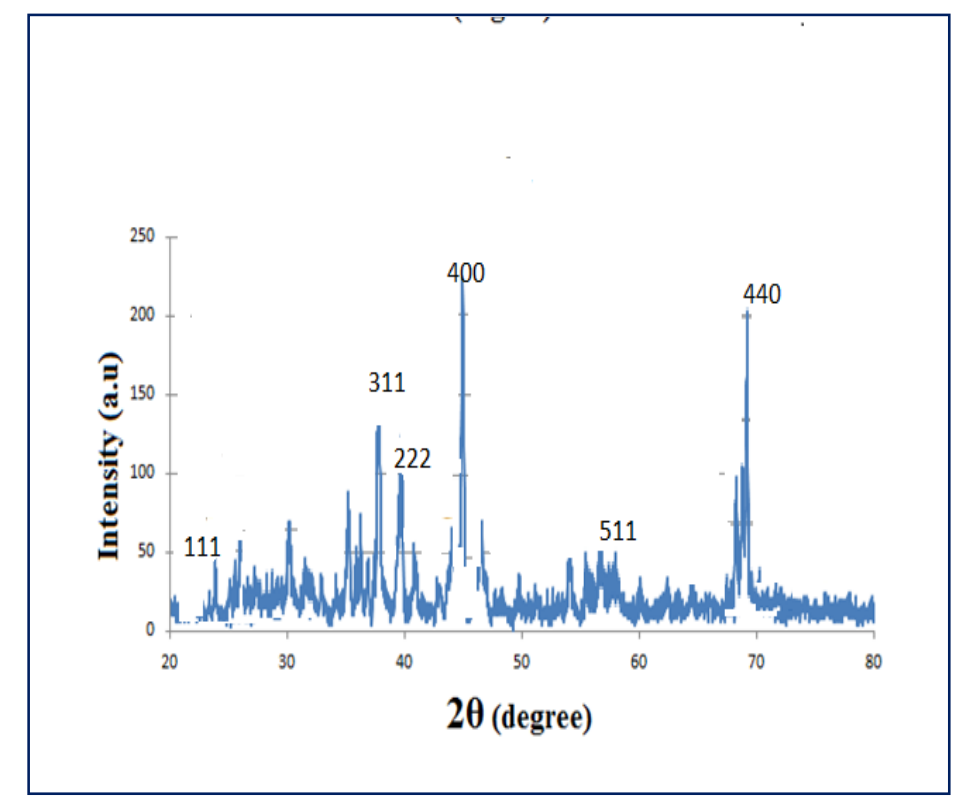

Fig. (1): Illustrate the X-Ray of Aluminum Oxide nanoparticles.

II. Atomic Force Microscopy (AFM) Figure (2) show the atomic force microscope results for $\mathrm{AL}_{2} \mathrm{O}_{3}$ which had been prepared in UV-irradiation with different thickness, one can observe that the particle size was variated from $25.97-65 \mathrm{~nm}$.
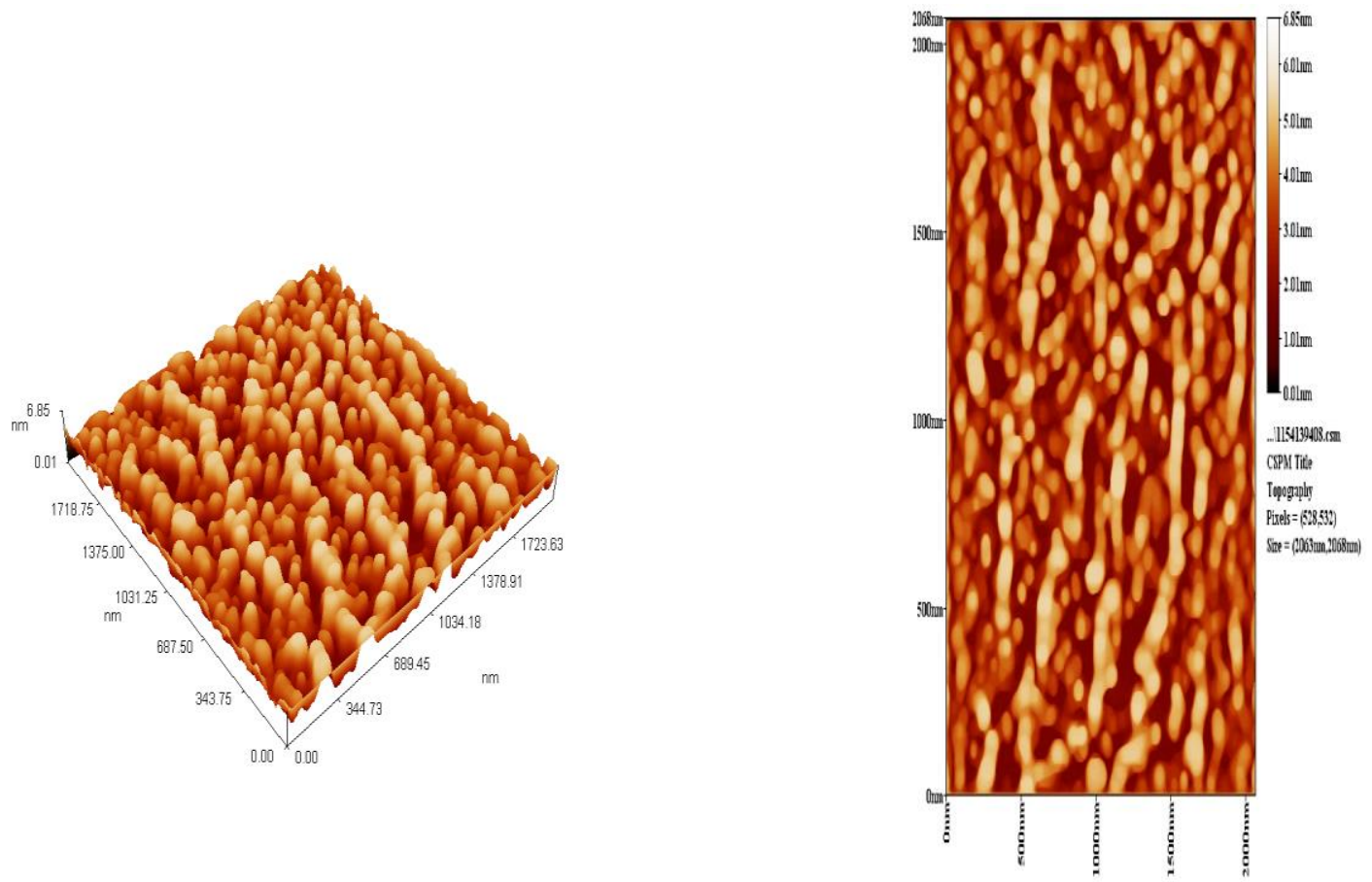

Fig. 2: illustrated the AFM results for $\mathrm{Al}_{2} \mathrm{O}_{3}$ nanoparticles. 
3-Optical Results

Figure (3) showed the absorbance spectra of $\left(\mathrm{Al}_{2} \mathrm{O}_{3}\right)$ nanoparticles with wavelength range (200-800) $\mathrm{nm}$ is represented so, the absorbance with the increase of the thickness ${ }^{[5,6]}$.

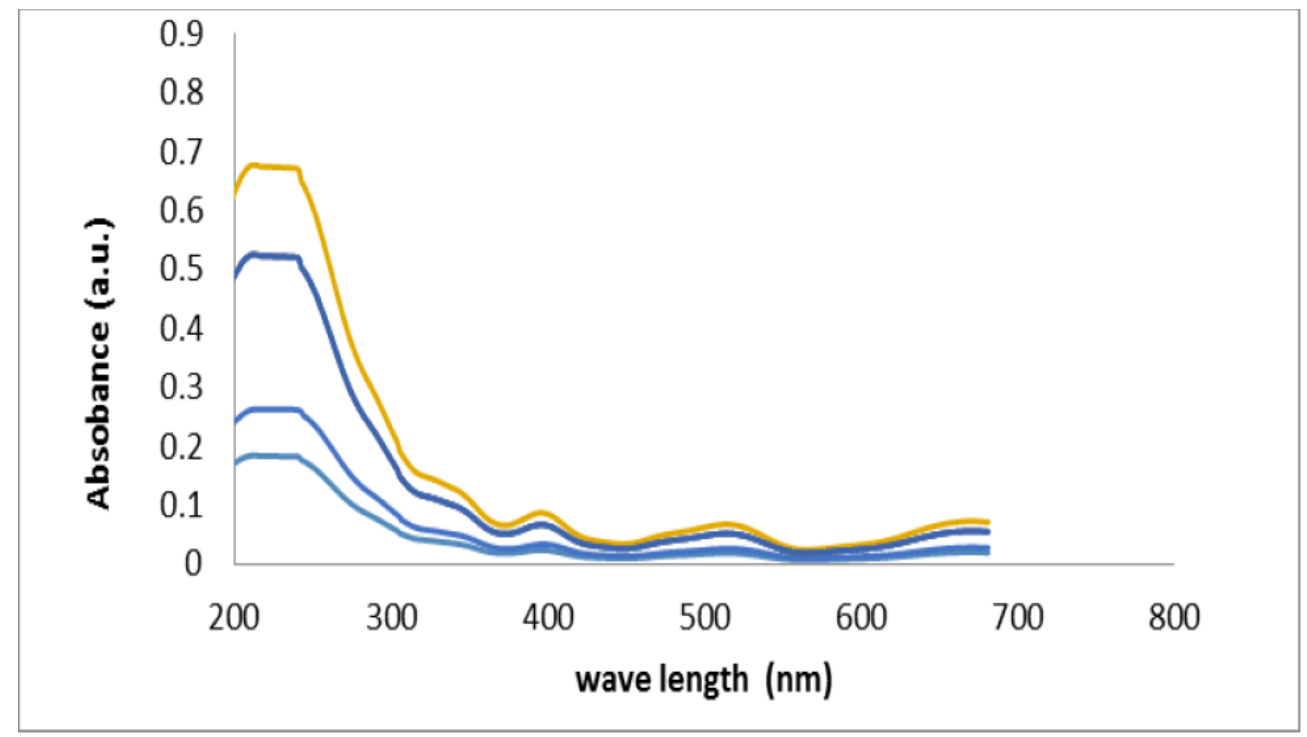

Fig. (3) Absorption Spectrum, of $\mathrm{Al}_{2} \mathrm{O}_{3}$ nanoparticles.

4- Calculate the Energy Gap

To find the values of energy gap by drawing curves between $(\alpha h v)^{1 / 2}$ as function of energy (hv). Then tacking touch line from $(\alpha h v)^{1 / 2}=0$ this values represent Eq as shown in figure (4) from results we showed that values of energy gaps decreased with increasing nana silver percent this refers to intermediate levels which contains when added materials which increasing electrons charge ${ }^{[7]}$.

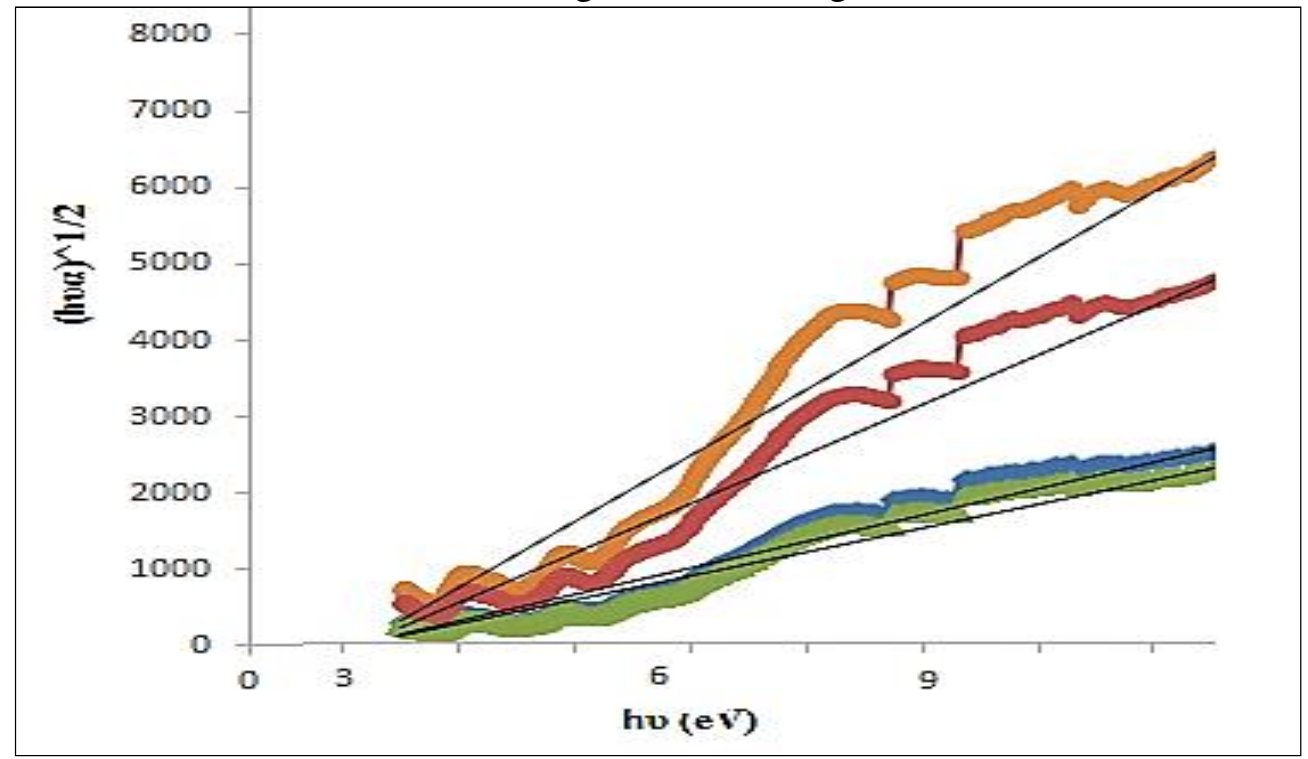

Fig. (4) showed values of energy gap.

where values of energy gap equal to (5.19-4.68) eV from different thickness.

5.Thin films of $\mathrm{Al}_{2} \mathrm{O}_{3}$ nanoparticles used as gas sensors

Using $\mathrm{Al}_{2} \mathrm{O}_{3}$ nanoparticles as sensor sensitivity before and after the deposition of catalysts is shown in figure (5) for understanding the effect of the platinum coating on sensitivity of $\mathrm{Al}_{2} \mathrm{O}_{3}$ nanoparticles to ammonium gas (NH3). From results appeared that increasing in the thickness of the depletion layer increased each of the resistance and sensitivity of $\mathrm{Al}_{2} \mathrm{O}_{3}$. 


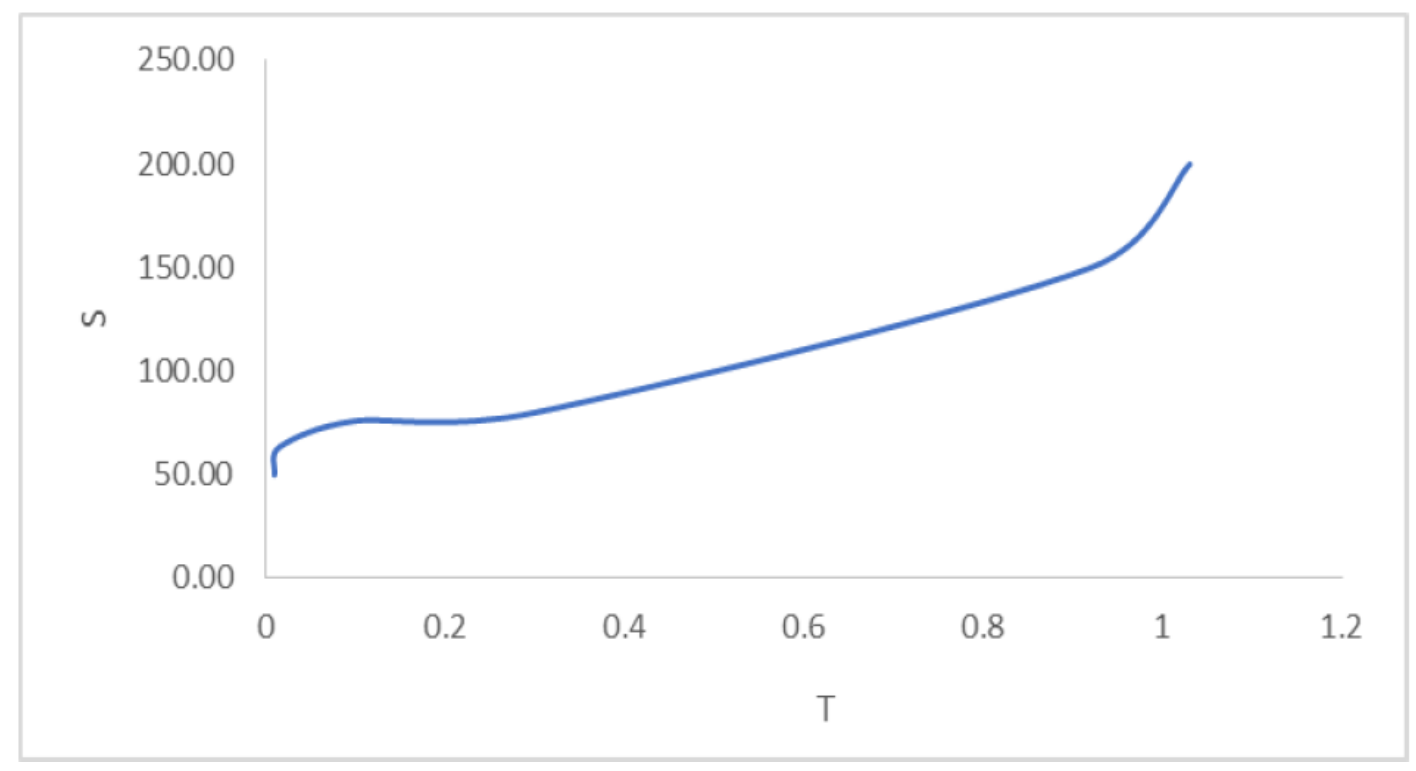

Fig. (5) Sensor sensitivity of the $\mathrm{Al}_{2} \mathrm{O}_{3}$ on $\mathrm{NH}_{3}$ gas

From the result in figure (5) the resistance and sensor sensitivity to $\mathrm{NH} 3$ as increased linearly with increasing temperature.

\section{Conclusion:}

1. The UV-irradiation methods for prepared nanoparticles consider as an environmentally friendly method.

2. The grain size of aluminum oxide nanoparticle about 25.97 - $65 \mathrm{~nm}$ increased with increasing thickness of thin films.

3. The absorbance of $\left(\mathrm{Al}_{2} \mathrm{O}_{3}\right)$ nanoparticle increases have higher absorbance in the $\mathrm{UV}$ region.

4.Energy gaps of nanoparticles increased energy gaps with thickness from 4.68 to $5.19 \mathrm{eV}$.

5.The gas sensitivity is proportional with the thickness of films so the aluminum oxide nanoparticles consider a good gas sensors for NH3 gas .

\section{References}

1. David J. Mandia1, Wenjun Zhou, Matthew J. Ward, Howie Joress, Jeffrey J. Sims, Javier B. Giorgi4, Jacques Albert, and Seán T. Barry, The Effect of ALD-grown $\mathrm{Al}_{2} \mathrm{O}_{3}$ on the Refractive Index Sensitivity of CVD Goldcoated Optical Fiber Sensors, Nanotechnology, 26 ,43,1-32, 2015.

2. Otto M, Kroll M, Käsebier T, Ziegler J, Sprafke A N and Wehrspohn R.B ,Passivation of Optically Black Silicon by Atomic Layer Deposited $\mathrm{Al}_{2} \mathrm{O}_{3}$ Energy Procedia 38 862-5 2013.

3. Majid, F., Riaz, S. and Naseem, S., Optical properties of Electrodeposited alumina thin films by using Spectroscopic Ellipsometer, Appl. Mech. Mater., 319, 8489 ,2013.

4. 4.Rajesh Choudhary, Adarsh Saini and Sudhakar Subudhi, Experimental Investigation of Natural Convection in an Enclosure with water and $\alpha-\mathrm{Al}_{2} \mathrm{O}_{3}$ /Water Nanofluid for Different Aspect Ratios, Proceedings of the Forty Second National Conference on Fluid Mechanics and Fluid Power NITK Saratha, Karnataka, India - 22, 2016.

5. 5.EL-Malawian. R, Abdallah. M. D Abbas. A. I, Materials Chemistry Physics, 109, pp. 291-296,2008.

6. 6.R. K. Fakher Alfahed, K.I. Ajeel, International Journal of Technology Enhancements and Emerging Engineering Research, Issue 08, 3, ISSN 2347-4289 pp.36-41,2015.

7. 7.K. Jhansi, S. Chandralingam, N. Manohar Reddy, Padma Suvarna, Ch. Ashok, K. Venkateswara Rao, J. of Nanotech. and Mater. Sci., 3,1, 2016. 